\title{
RESULTS FROM FILLING "REMPLISSAGE" ARTHROSCOPIC TECHNIQUE FOR RECURRENT ANTERIOR SHOULDER DISLOCATION
}

Mauro Emilio Conforto Gracitelli ${ }^{1}$, Camilo Partezani Helito ${ }^{2}$, Eduardo Angeli Malavolta' ${ }^{1}$ Arnaldo Amado Ferreira Neto ${ }^{3}$, Eduardo Benegas', Flávia de Santis Prada ${ }^{1}$, Augusto Tadeu Barros de Sousa ${ }^{4}$, Jorge Henrique Assunção ${ }^{5}$, Edwin Eiji Sunada ${ }^{5}$

\section{ABSTRACT}

Objective: To evaluate the clinical result from the filling ("remplissage") technique in association with Bankart lesion repair for treating recurrent anterior shoulder dislocation. Methods: Nine patients (10 shoulders), with a mean follow-up of 13.7 months, presented traumatic recurrent anterior shoulder dislocation. All of them had a Bankart lesion, associated with a Hill-Sachs lesion showing the "engaging" sign. The Hill-Sachs lesion defect was measured and showed an average bone loss of $17.3 \%(7.7 \%$ to $26.7 \%)$ in relation to the diameter of the humeral head. All the cases underwent arthroscopic repair of the Bankart lesion, together with filling of the Hill-Sachs lesion by means of tenodesis of the infraspinatus. Results: The Rowe score ranged from 22.5 (10 to 45 ) before the operation to 80.5 (5 to 100) after the operation $(p<0.001)$. The UCLA score ranged from 18.0 (8 to 29$)$ to 31.1 (21 to 31$)(p<0.001)$. The measurements of external and internal rotation at abduction of $90^{\circ}$ after the operation were $63.5^{\circ}\left(45^{\circ}\right.$ to $\left.90^{\circ}\right)$ and $73^{\circ}\left(50^{\circ}\right.$ to $\left.92^{\circ}\right)$ respectively. Two patients presented recurrence (one with dislocation and the other with subluxation). None of the patients presented pain in the region of the infraspinatus tendon after the operation. Conclusion: Over the short term, the filling ("remplissage") arthroscopic technique produced improvements in functional scores and a low complication rate when used for treating glenohumeral instability associated with Hill-Sachs lesions.

Keywords - Joint Instability; Shoulder Dislocation/epidemiology; Shoulder Dislocation/surgery; Arthroscopy; Recurrence

The HS lesion is a compression fracture in the posterosuperior lateral region of the humeral head ${ }^{(5)}$. Its incidence in acute anterior dislocation is estimated as $47 \%$ to $80 \%$ and, in recurrent dislocation, it is present in up to $93 \%$ of the cases ${ }^{(1,4,6)}$. This lesion changes the spherical format of the humeral head, and, depending on its format and extension, can decrease the articular arc of excursion of the humeral head in relation to the glenoid cavity in the position of abduction and lateral rotation. In this situation it engages easily on its anterior edge, leading to the dislocation ${ }^{(7,8)}$.

1 - Assistant Physician of the Shoulder and Elbow Group of the Institute of Orthopedics and Traumatology of HC/FMUSP - São Paulo, SP.

2 - Resident Physician of the Shoulder and Elbow Group of the Institute of Orthopedics and Traumatology of HC/FMUSP - São Paulo, SP.

3 - Assistant Physician and Head of the Shoulder and Elbow Group of the Institute of Orthopedics and Traumatology of HC/FMUSP - São Paulo, SP.

4 - Orthopedist in Training of the Shoulder and Elbow Group of the Institute of Orthopedics and Traumatology of HC/FMUSP - São Paulo, SP.

5 - Orthopedists and Preceptors of the Shoulder and Elbow Group of the Institute of Orthopedics and Traumatology of HC/FMUSP - São Paulo, SP.

Study conducted at LIM 41 - Laboratory of Medical Investigation of the Musculoskeletal System of the Department of Orthopedics and Traumatology of the School of Medicine of Universidade de São Paulo.

Mailing address: Rua Dr. Ovídio Pires de Campos, 333, Cerqueira Cesar - 05403-010 - São Paulo, SP. Email: mgracitelli@gmail.com. Study received for publication: $2 / 2 / 2011$, accepted for publication: $5 / 25 / 2011$.

The authors declare that there was no conflict of interest in conducting this work 
These lesions, particularly those considered large (involving more than $20 \%$ of the humeral head surface), when not treated, increase the risk of postoperative recurrence after the isolated repair of the BK lesion ${ }^{(2)}$. This also occurs in the presence of bone lesions of the anterior edge of the glenoid cavity, surpassing $25 \%$ of its diameter ${ }^{(2,9)}$.

The treatment of the HS lesion has always been a challenge due to its location, which hinders less aggressive surgical access, and due to the technical difficulties of filling the lesion (use of bone, autologous osteocartilaginous or tissue bank graft).

In 1972, Connoly ${ }^{(10)}$ proposed the open surgical treatment of the HS lesion, performing tenotomy of the infraspinatus tendon and suturing it on the bone defect of the HS lesion, like McLaughlin's surgery in the treatment of posterior shoulder dislocation.

Based on this technique, Purchase et $a l^{(11)}$ idealized a procedure, called "remplissage", for the arthroscopic treatment of the HS lesion. This French term, which means filling, or padding, was used to define this technique that consists of suturing the tendon of the infraspinatus muscle (tenodesis) at the site of the defect together with the arthroscopic repair of the BK lesion. The objective of this suturing is to prevent the HS from engaging onto the anterior edge of the glenoid cavity in the abduction and external rotation movement ${ }^{(11)}$.

The aim of this study was to retrospectively evaluate the clinical result of the "remplissage" technique associated with repair of the BK lesion for treatment of recurrent anterior shoulder dislocation.

\section{MATERIAL AND METHODS}

\section{Methods}

Nine patients (10 shoulders) diagnosed with recurrent anterior shoulder dislocation of traumatic origin, submitted to the "remplissage" procedure in association with repair of the BK lesion, were evaluated retrospectively. They were all operated at the Orthopedics Institute of Hospital das Clínicas, in the period from January 2006 to December 2009.

The mean follow-up time was 13.7 months (six to 28 months). Seven patients were male and two female. An operation was performed on five right shoulders, and five left shoulders, of which four were of the dominant limb. The patients' age averaged 33.4 years (23 to 56 years). The patients presented an average of 19.5 dislocation episodes (two to 55). Preoperative computed arthrotomography scans were performed in eight cases, and nuclear magnetic resonance imaging in two cases.

All the lesions (BK and HS) were diagnosed by magnetic resonance (MR) or computed arthrotomography.

We evaluated the size of the HS lesion in the axial sections of the arthrotomography or MR, as follows: we based our evaluation on the axial section that presented the longest extension of HS lesion; in the same section, we traced the total circumference of the humeral head, using its uninjured portion as a reference; we measured the diameter of the head - segment $A B$ and the depth of the defect - segment BC; the percentage of bone defect was calculated by the formula $\mathrm{BC} /$ $\mathrm{AB} \times 100$ (Figure 1).

The articular arc of the humeral head can be defined as the angle formed between the limits of the anterior and posterior articular cartilage of the humeral head in an axial section of the arthrotomography or MR, considering the center of the humeral head as the axis. The axial section was chosen in the area with largest lesion, limited to $25 \mathrm{~mm}$ from the top of the head. As demonstrated in Figure 2, the first step consists of marking the center of the humeral head. For this purpose, a circle is superimposed on the humeral head, and its center is marked. After this, the anterior and posterior limits of the cartilage are marked. Two lines are drawn between the anterior and posterior limits of the cartilage and the center of the head, and the angle formed here is measured.

The "engaging" HS lesion was evaluated under direct view at the start of the arthroscopic treatment, through the engagement maneuver that consists of positioning the shoulder in abduction of $90^{\circ}$ and external rotation of $90^{\circ}$, observing the easy engagement of the HS on the anterior edge of the glenoid cavity (Figure 3).

All the patients presented bone lesion of the anterior edge of the glenoid cavity below $20 \%$ in relation to its anteroposterior diameter. This measurement was performed in the intraoperative stage with a probe marked in millimeters using the technique described by Burkhart ${ }^{(12)}$.

Cases with rotator cuff lesions, fractures of the proximal third of the humerus and bone lesions of the glenoid cavity above $20 \%$ were not included. 


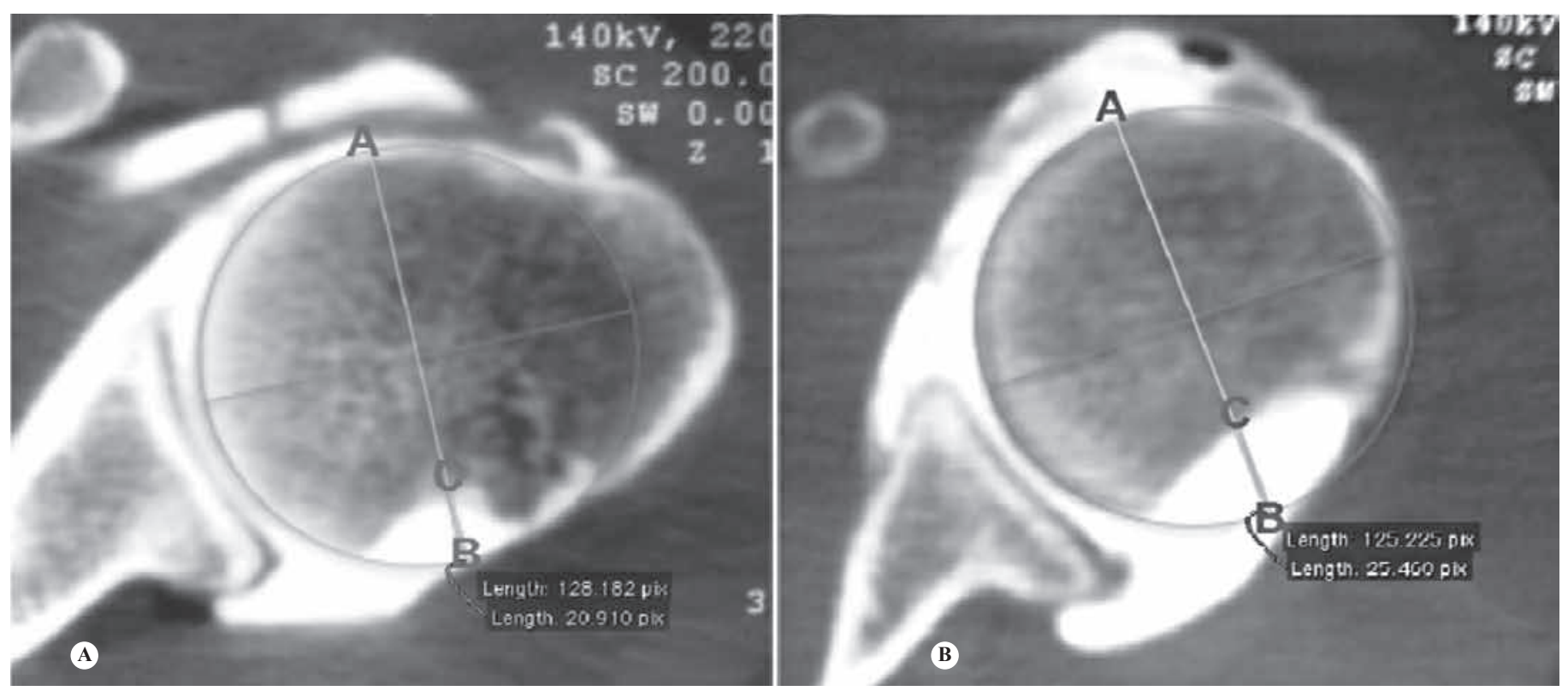

Figure 1 - Measurement of the depth of the HS lesion. Segment AB: diameter of the humeral head; segment BC: depth of the defect. (A) $B C=20.9 ; A B=128.2$; defect $=16.3 \%$. (B) $B C=25.5 ; A B=125.2$; defect $=20.4 \%$.

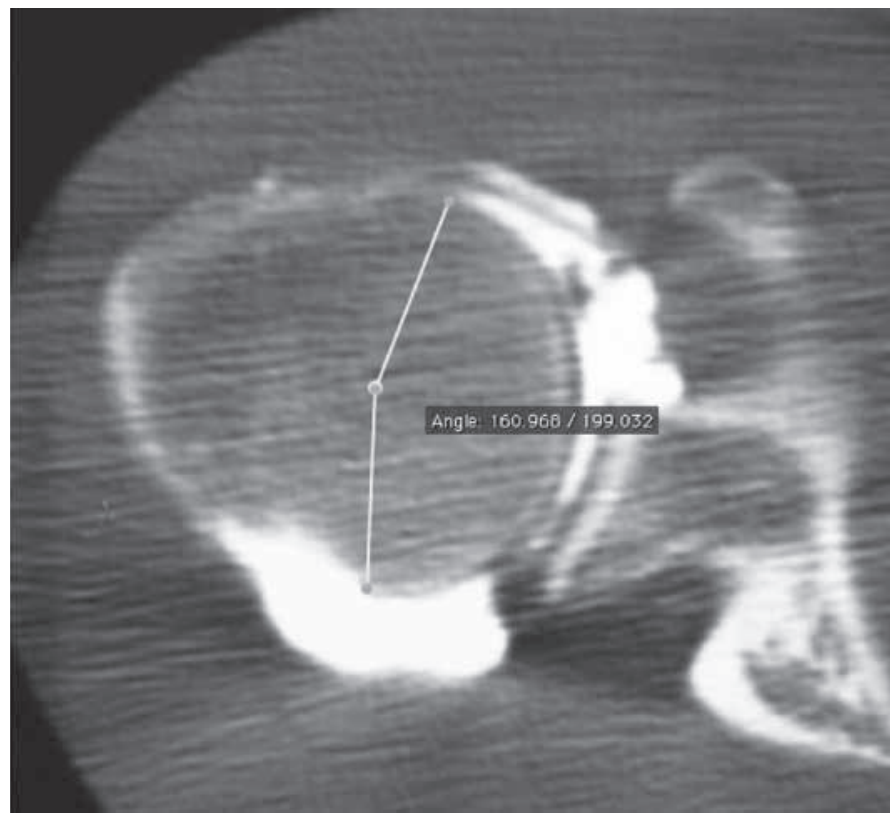

Figure 2 - Articular arc of humeral head.

The patients were clinically evaluated in the pre- and postoperative stages, using the ROWE and UCLA scores. Healing of the infraspinatus tenodesis ("remplissage" procedure) was evaluated by MR.

\section{Surgical technique}

The surgical technique performed was the same described by Purchase et $a l^{(11)}$. The surgery begins with an articular inspection, confirming the engagement of the HS lesion on the anterior edge of the glenoid cavity after maximum external rotation with

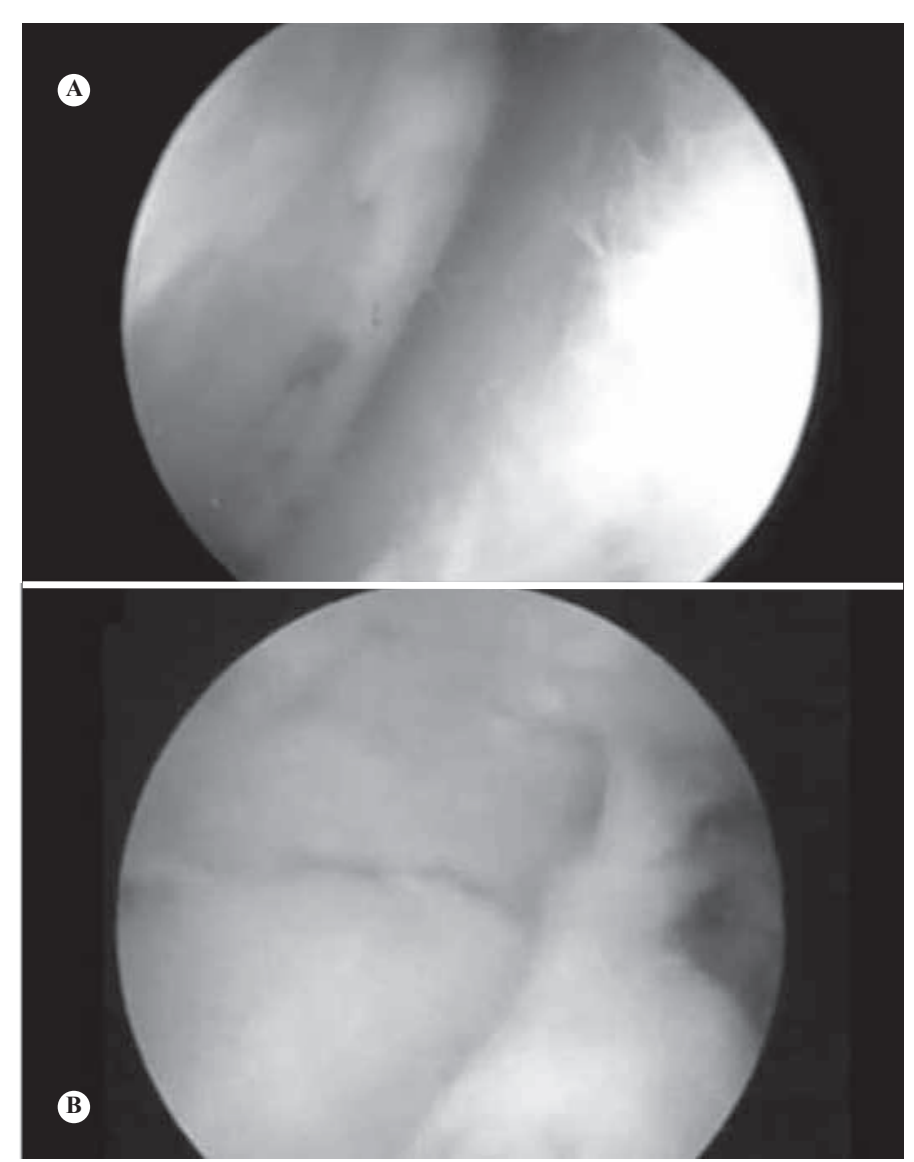

Figure 3 - Engaging HS maneuver, performed with abduction and external rotation of $90^{\circ}$, demonstrated with visualization through the posterior $(A)$ or anterosuperior $(B)$ portal.

the arm at $90^{\circ}$ of abduction. The degree of bone lesion of the glenoid cavity was measured using Burkhart's technique, followed by the repair of the BK lesion 
using a standard technique with anchors. After this stage, infraspinatus tenodesis was performed in the humeral head defect as follows: visualization through the anterolateral portal and measurement of the size of the HS lesion for calculation of the number of anchors to be used; debridement of the lesion, through the standard posterior portal, with a bone shaver, obtaining a bleeding bone surface (be careful not to deepen the lesion); through the same portal, placement of the $5.5 \mathrm{~mm}$ anchor(s) around $3 \mathrm{~mm}$ from the edge of the articular surface, vertically in relation to the HS lesion and according to its size. Two anchors were used on average. Then, the posterior cannula is backed out of the joint, with juxtaposition on the surface of the infraspinatus tendon; passage of straight bird-beak arthroscopic suture passers through the tendon and capturing of the suture threads making a "U" shaped stitch (the quantity of tissue from the tendon to be sutured should be as large as possible); making of slipknots observing the filling of the lesion (Figure 4).

The physiotherapy protocol consisted of keeping the shoulder immobilized with a Velpeau sling for four weeks, allowing active movements of the elbow, wrist and fingers. Passive and passive-assisted exercises were introduced after this period for gain of movement. Muscle strengthening was only started after the eighth week.

\section{Statistical analysis}

After the performance of the normality test (Shapiro-Wilk), it was verified that there were data whose distribution did not allow approximation for Gaussian distribution, and the organizers decided to use nonparametric tests. The comparison between the values of the UCLA and ROWE scales between the pre- and postoperative periods was performed by the Wilcoxon test. The correlations between the pre- and postoperative values of ROWE and UCLA and the values of the residual articular angle of the head and of the percentage loss of the head diameter were performed by the Spearman test.

The significance level of $5 \%(\alpha=0.05)$ was adopted in all the cases.

\section{RESULTS}

We analyzed 10 shoulders of nine patients submitted to the "remplissage" procedure. In the evaluation of the bone defect of the glenoid cavity, all the individuals presented lesion of the lower anterior edge at $20 \%$ of the diameter. The mean residual articular arc of the humeral head was $150.9^{\circ}\left(119\right.$ to $\left.169^{\circ}\right)$. The percentage of loss of the diameter of the humeral head averaged $17.3 \%$ ( 7.7 to $26.8 \%$ ). The mean depth of the HS lesion was $20.4 \mathrm{~mm}(5.6 \mathrm{~mm}$ to $35.7 \mathrm{~mm})$ (Table 1).

Two anchors were used in four cases and one in six cases for posterior capsule and infraspinatus tendon fixation in the HS defect.

The patients presented a mean preoperative ROWE score of 22.5 points (10 to 45 ) and a mean preoperative UCLA score of 18 points (8-29). The mean postoperative ROWE score was 80.5 points ( 5 to 100 ) and the UCLA score was 31.1 points (21-35) (Table $2)$. The improvement after the surgical procedure was statistically significant for both scores, through the Wilcoxon test $(p<0.001)$.

The pre- and postoperative clinical scores (ROWE and UCLA) were correlated with the different preope-
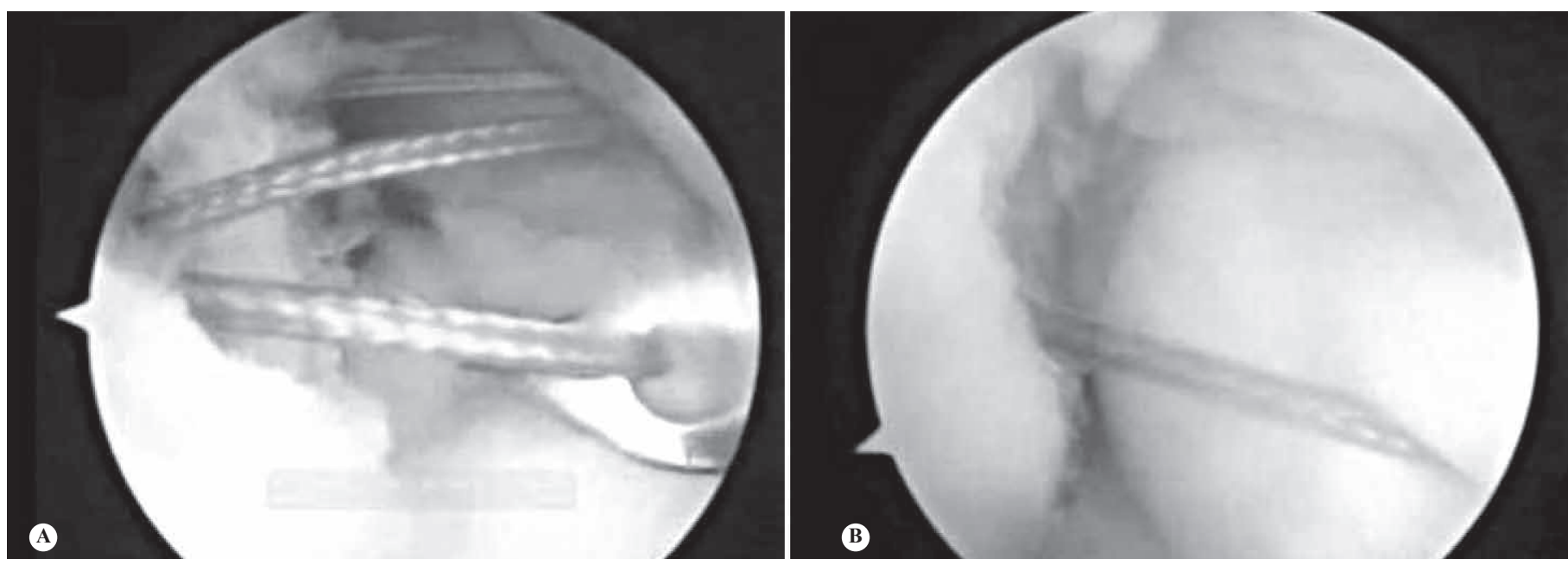

Figure 4 - Arthroscopic visualization through the anterosuperior portal. (A) Passage of the stitches through the posterior capsule and infraspinatus tendon; (B) Suturing and filling of the HS. 
rative HS measurements (residual articular angle and percentage of loss of the head diameter) through the Spearman test. There was statistically significant correlation between the preoperative UCLA score and the residual articular angle and between the postoperative ROWE score and the percentage of loss of the head diameter $(\mathrm{p}=0.0021$ and $\mathrm{p}=0.0201$ respectively). The other correlations were not significant.

As regards the postoperative range of motion, the mean external rotation at $90^{\circ}$ of abduction was $64^{\circ}$ $\left(45^{\circ}\right.$ to $\left.90^{\circ}\right)$ and the internal rotation at $90^{\circ}$ of abduction was $73^{\circ}\left(50^{\circ}\right.$ to $\left.90^{\circ}\right)$. No patient presented pain on the posterior side of the shoulder and in the infraspinatus topography or neurovascular complications.

Two patients presented recurrence of the instability. In one case, subluxation symptoms started nine months after surgery, while the patient was performing abduction and external rotation activities, without a history of trauma. In this individual, the loss of head diameter was $18.9 \%$. Only one patient presented

Table 1 - Measurement of the Hill-Sachs lesion.

\begin{tabular}{c|c|c|c}
\hline Case & $\begin{array}{c}\text { Residual articular } \\
\text { arc (degrees) }\end{array}$ & $\begin{array}{c}\text { Loss of head diam- } \\
\text { eter (\%) }\end{array}$ & $\begin{array}{c}\text { Depth of the HS } \\
(\mathbf{m m})\end{array}$ \\
\hline 1 & 156 & 0.6 & 18.7 \\
\hline 2 & 169 & 1.2 & 15.4 \\
\hline 3 & 146.7 & 2.0 & 20.9 \\
\hline 4 & 159 & 2.5 & 25.5 \\
\hline 5 & 162 & 3.1 & 20.4 \\
\hline 6 & 148 & 4.1 & 5.6 \\
\hline 7 & 151 & 4.6 & 16.4 \\
\hline 8 & 160 & 5.0 & 35.7 \\
\hline 9 & 138 & 6.5 & 15.1 \\
\hline 10 & 119 & 8.4 & 30.5 \\
\hline
\end{tabular}

Table 2 - Pre- and postoperative scores and recurrence.

\begin{tabular}{c|c|c|c|c|c|c}
\hline Case & $\begin{array}{c}\text { Follow-up } \\
\text { (months) }\end{array}$ & $\begin{array}{c}\text { Preop } \\
\text { ROWE }\end{array}$ & $\begin{array}{c}\text { Postop } \\
\text { ROWE }\end{array}$ & $\begin{array}{c}\text { Preop } \\
\text { UCLA }\end{array}$ & $\begin{array}{c}\text { Postop } \\
\text { UCLA }\end{array}$ & Recurrence \\
\hline 1 & 12 & 10 & 70 & 19 & 26 & No \\
\hline 2 & 12 & 45 & 80 & 27 & 34 & $\begin{array}{c}\text { Yes } \\
\text { (subluxation) }\end{array}$ \\
\hline 3 & 19 & 20 & 95 & 13 & 33 & No \\
\hline 4 & 12 & 25 & 95 & 19 & 35 & No \\
\hline 5 & 9 & 45 & 95 & 29 & 35 & No \\
\hline 6 & 6 & 10 & 100 & 8 & 35 & No \\
\hline 7 & 9 & 15 & 90 & 19 & 29 & No \\
\hline 8 & 21 & 15 & 80 & 19 & 30 & No \\
\hline 9 & 9 & 15 & 95 & 11 & 33 & No \\
\hline 10 & 28 & 25 & 5 & 16 & 21 & Yes \\
\hline
\end{tabular}

new episodes of dislocation. Recurrence started 10 months after surgery, during a seizure, despite the healing of the "remplissage". This patient presented $26.8 \%$ of loss of head diameter and residual articular $\operatorname{arc}$ of $119^{\circ}$. The patient was submitted to the Latarjet procedure, evolving without complications and without recurrence.

Of the five patients who performed postoperative MR, three $(60 \%)$ presented clear signs of healing of the tenodesis in the HS defect. Two of these patients presented recurrence $(66 \%)$ after the NMR. Two patients $(40 \%)$ did not present clear signs of tenodesis healing, yet did not present recurrence of the dislocation (Figure 5).

\section{DISCUSSION}

Defects of the articular surface of the humeral head and their relationship with shoulder dislocation were described in literature even before Hill and Sachs ${ }^{(5)}$. However, the influence of HS lesions on the recurrence of anterior shoulder dislocation is controversial. Classically, authors such as Bankart ${ }^{(13)}$ did not consider the HS lesion a significant factor for the recurrence of dislocation. Burkhart and De Beer ${ }^{(2)}$, however, demonstrated that bone lesions of the humerus or of the glenoid cavity can contribute towards recurrence, in spite of the adequate arthroscopic repair of the labrum lesion. These authors demonstrated that, in cases in which there is bone lesion of the glenoid cavity above $25 \%$ or engaging sign during arthroscopic visualization, the isolated repair of the BK lesion presents a high rate of recurrence, as high as $67 \%$ against $4 \%$ of recurrence in cases without bone lesion ${ }^{(2)}$.

The evaluation of the degree of humeral bone lesion is controversial. The HS lesion can also be classified according to the percentage of bone loss of the humeral head diameter: slight $(20 \%)$, moderate $(20$ to $45 \%)$ and severe $(>45 \%)^{(14)}$. In our study, we evaluated the percentage of loss of the humeral head diameter, the depth of the HS lesion and the residual articular arc through the axial section with the largest lesion (limited to $25 \mathrm{~mm}$ from the top of the head). We obtained a mean percentage of $17.3 \%$ ( 7.7 to $26.8 \%$ ) of bone loss from the head. Three cases would be classified as moderate and the other cases (seven cases) as slight. Of the three cases with moderate HS, one case presented recurrence after a seizure after 

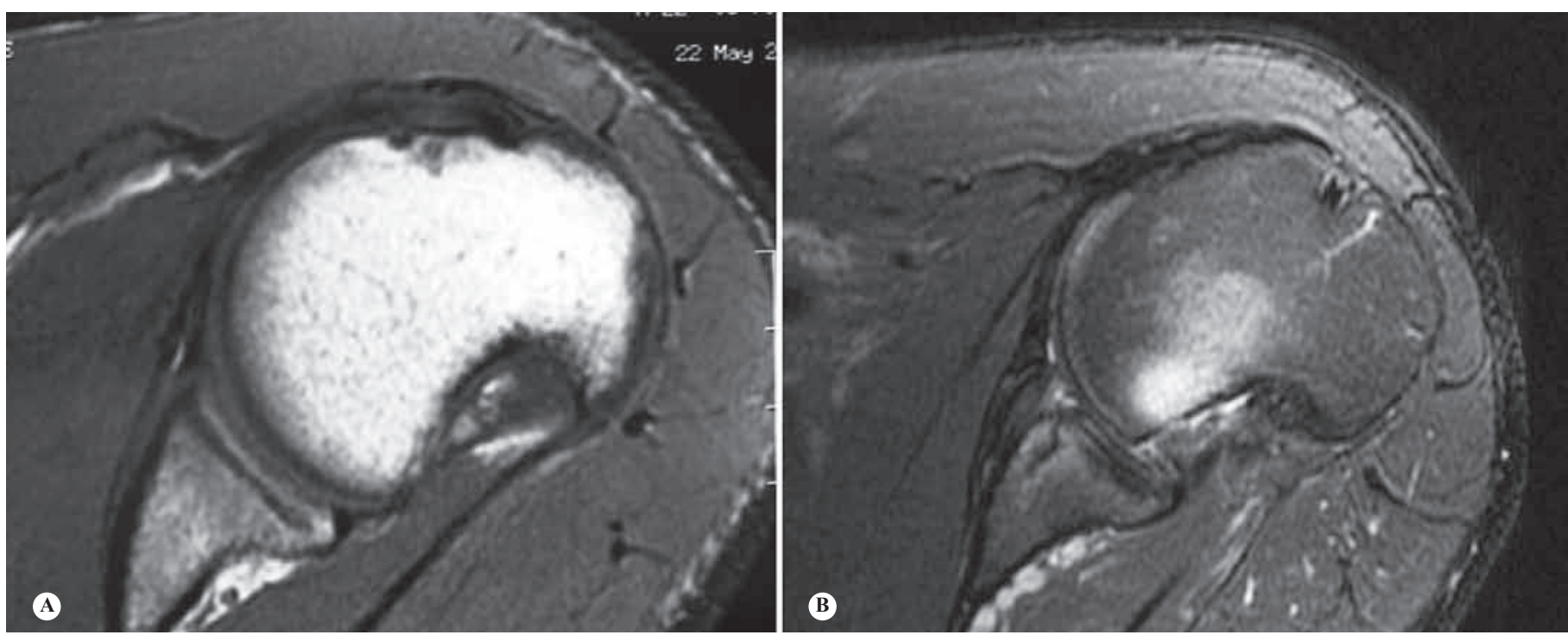

Figure 5 - Pre- (A) and postoperative (B) magnetic resonance scan of patient submitted to the "remplissage" procedure, with signs of healing of the infraspinatus tendon in the HS defec.

10 months of follow-up. However, all the cases presented the engaging HS sign in the absence of the inverted-pear sign and with bone lesions of the glenoid cavity below $25 \%$. The correlations appeared statistically significant only between the preoperative UCLA score and the residual articular $\operatorname{arc}(\mathrm{p}=0.0021)$, and between the postoperative ROWE score and the percentage loss of head diameter $(p=0.0201)$. These correlations demonstrate the importance of the size of the HS lesion, whether it is measured through the residual articular arc or through the head diameter, in the preoperative clinical picture, which is an important criterion of severity. The lack of correlation in the other analyses may perhaps be due to the small study sample. In our opinion, the different measurements of HS, the existing classifications and their correlation with the intraoperative evaluation are still controversial and should be studied in more depth.

Humeral head reconstruction or approach indications are also controversial. HS lesions have historically been approached only after the failure of the previous repair of soft parts. Primary approaches to HS lesion have been implemented recently with the objective of decreasing the recurrence of cases with bone lesions.

The size of the HS lesion, considered borderline for the performance of the BK lesion repair separately, is variable in literature. Most authors consider the limit for non-approach to the HS lesion to be $20 \%$, but values between $12.5 \%$ and $30 \%$ of head diameter loss are mentioned $^{(3,9,15)}$. Other authors, such as Balg and Boileau ${ }^{(16)}$, use a combination of clinical and radiographic criteria as an indication for the approach to bone lesions both of the humerus and of the glenoid cavity.

In our sample, we considered the following criteria for performance of the "remplissage" procedure: lesions of the glenoid cavity below $25 \%$ of the diameter (by arthrotomography, MR or arthroscopic evaluation); HS lesions present in the arthrotomography or in the MR; engaging sign during the arthroscopic evaluation.

Several techniques are described in literature for approach to the HS lesion, such as: external derotation humeral osteotomy ${ }^{(17)}$, anterior capsuloplasty creating limitation of external rotation ${ }^{(2)}$, humeroplasty ${ }^{(18)}$, filling of the HS lesion, with soft parts or bone graft ${ }^{(15,19)}$, partial humeral head prostheses or the Bristow procedure ${ }^{(20,21)}$. However, most of the abovementioned procedures are technically difficult and some may require a posterior approach. Moreover, it may be necessary to have a simultaneous or sequential anterior approach for the treatment of labrum and ligament lesions. Potential setbacks can occur in the postoperative period, prolonging rehabilitation and generating possible limitations in the range of motion $^{(2,15,17,18)}$. Other complications, such as postoperative infection, synthesis material working loose and secondary rigidity are described with these techniques ${ }^{(2,15,17,18)}$.

Toro et $a l^{(22)}$ described the method for performing tenodesis by intra-articular visualization, without the need for subacromial visualization. The authors reported a good clinical result, without complications related to the procedure. Koo et $a l^{(23)}$ described a similar technique, in which the tendon was sutured with two anchors, with stitches that were further apart in the infra- 
spinatus tendon, using the double-pulley suture-bridge technique. The author visualized the suture through the extra-articular space, to allow a safer knot. The same author reports a low rate of complications with this procedure. In our cases, we did not routinely visualize the stitches through the subacromial space, without noticing problems during their performance.

As advantages of the "remplissage" technique, we can say that the procedure adds little operative time to the arthroscopic repair of BK, and does not change the standard technique, without important technical difficulties. As the procedure is entirely arthroscopic, it has the advantage of less surgical invasiveness and, consequently, a lower rate of infection, allowing early rehabilitation.

Some authors reported a decrease of joint mobility, mainly limitations of internal and external rotation ${ }^{(24)}$. On the other hand, other authors did not encounter internal rotation limitations ${ }^{(23)}$. In our sample, we demonstrated a low incidence of internal and external rotation limitation.

As regards the healing of the tendon and the head defect, we did not find any postoperative evaluation through any imaging method in literature. In our

\section{REFERENCES}

1. Tauber M, Resch H, Forstner R, Raffl M, Schauer J. Reasons for failure after surgical repair of anterior shoulder instability. J Shoulder Elbow Surg. 2004;13(3):279-85.

2. Burkhart SS, De Beer JF. Traumatic glenohumeral bone defects and their relationship to failure of arthroscopic Bankart repairs: significance of the inverted-pear glenoid and the humeral engaging Hill-Sachs lesion. Arthroscopy. 2000;16(7):677-94.

3. Kropf EJ, Tjoumakaris FP, Sekiya JK. Arthroscopic shoulder stabilization: is there ever a need to open? Arthroscopy. 2007;23(7):779-84.

4. Bushnell BD, Creighton RA, Herring MM. The bony apprehension test for instability of the shoulder: a prospective pilot analysis. Arthroscopy. 2008;24(9):1061-73.

5. Hill HA, Sachs MD. The groove defect of the humeral head. A frequently unrecognized complication of dislocations of the shoulder joint. Radiology. 1940;35:690-700.

6. Chen AL, Hunt SA, Hawkins RJ, Zuckerman JD. Management of bone loss associated with recurrent anterior glenohumeral instability. Am J Sports Med. 2005;33(6):912-25.

7. Burkhart SS, Danaceau SM. Articular arc length mismatch as a cause of failed bankart repair. Arthroscopy. 2000;16(7):740-4.

8. Itoi E, Lee S, Berglund L, Berge L, An K. The effect of a glenoid defect on anteroinferior stability of the shoulder after Bankart repair. A Cadaveric Study. J Bone Joint Surg Am. 2000;82(1):35-46.

9. Boileau P, Villalba M, Héry JY, Balg F, Ahrens P, Neyton L. Risk factors for recurrence of shoulder instability after arthroscopic Bankart repair. J Bone Joint Surg Am. 2006;88(8):1755-63.

10. Connoly JF. Humeral head defects associated with shoulder dislocation-Their diagnostic and surgical significance. Instr Course Lect. 1972;21:42-54

11. Purchase RJ, Wolf EM, Hobgood ER, Pollock ME, Smalley CC. Hill-sachs "remplissage": an arthroscopic solution for the engaging hill-sachs lesion. Arthroscopy. 2008;24(6):723-6.

12. Burkhart SS, Debeer JF, Tehrany AM, Parten PM. Quantifying glenoid bone loss arthroscopically in shouldert instability. Arthroscopy. 2002;18(5):488-491.

13. Bankart BA. Discussion on recurrent dislocation of the shoulder. J Bone Joint Surg Br. 1948;30(1):46-8. study we used the MR examination for this purpose; however, it was not possible to conduct the statistical analysis due to the small number of cases submitted to postoperative MR. We had a case of recurrence whose MR examination showed healing of the "remplissage". We believe that this occurred due to the new seizure episodes and also due to the severity of the HS lesion (26.7\%).

The main weak points of our study were short follow-up time, small sample and absence of control group.

The definitive indication of the "remplissage" procedure, in association with the repair of the BK lesion, is still under discussion. Prospective, randomized studies will be necessary to analyze the efficacy and the long-term safety of this procedure in the treatment of recurrent anterior shoulder dislocation.

\section{CONCLUSIONS}

The arthroscopic "remplissage" technique demonstrated improvement of functional scores and a low rate of complications in the treatment of glenohumoral instability associated with Hill-Sachs lesions in the short term.
14. Bigliani LU, Flatow EL,Pollock RG. Fractures of the proximal humerus. In Rockwood CA, Green DP, Bucholz RW, editors. Fractures in adults. 4th ed. Philadelphia: Lippincott-Raven; 1996. p. 1055-107.

15. Kropf EJ, Sekiya JK. Osteoarticular allograft transplantation for large humeral head defects in glenohumeral instability. Arthroscopy. 2007;23(3):322.e1-5.

16. Balg F, Boileau P. The instability severity index score. A simple pre-operative score to select patients for arthroscopic or open shoulder stabilisation. J Bone Joint Surg Br. 2007;89(11):1470-7.

17. Weber BG, Simpson LA, Hardegger F. Rotational humeral osteotomy for recurrent anterior dislocation of the shoulder associated with a large Hill-Sachs lesion. J Bone Joint Surg Am. 1984;66(9):1443-50.

18. Kazel MD, Sekiya JK, Greene JA, Bruker CT. Percutaneous correction (humeroplasty) of humeral head defects (Hill-Sachs) associated with anterior shoulder instability: a cadaveric study. Arthroscopy. 2005;21(12):1473-8.

19. Doneux PS, Miyazaki AN, Lemos PEG, Souza AS, Checchia SL. Tratamento da luxacao recidivante anterior de ombro: uso de enxerto osseo na deficiencia da glenoide. Rev Bras Ortop. 1997;32(9):675-82.

20. Oliveira C, Finelli CA, Santos MAM, Moretto RTS, Monteiro AC. Tratamento da luxacao anterior recidivante do ombro pela tecnica de Bristow-Latarjet. Rev Bras Ortop. 2001;36(10):375-80.

21. Helfet AJ. Coracoid transplantation for recurring dislocation of the shoulder. J Bone Joint Surg Br. 1958;40(2);198-202.

22. Toro F, Meleán P, Moraga C, Ruiz F, González F, Vaisman A. Remplissage: infraspinatus tenodesis and posterior capsulodesis for the treatment of Hill Sachs lesions: an all intraarticular technique. Techn Shoulder Elbow Surg. 2008;9(4):188-92.

23. Koo SS, Burkhart SS, Ochoa E. Arthroscopic double-pulley remplissage technique for engaging Hill-Sachs lesions in anterior shoulder instability repairs. Arthroscopy. 2009;25(11):1343-8.

24. Deutsch AA, Kroll DG. Decreased range of motion following arthroscopic remplissage. Orthopedics. 2008;31(5):492. 